\title{
An Empirical Study on Apology Strategies Adopted by Chinese EFL Learners
}

\author{
Liang Chu \\ School of Foreign Studies \\ Xi' an University \\ Xi' an China
}

\begin{abstract}
Due to his insufficiency in linguistic realization rules as well as social-appropriateness rules, a Chinese L2 learner, more often than not, opts to make an offence unconsciously in their daily conversation with a native speaker. In order to restore harmony, as is disputed by Wolfson (1989), the act of apologizing must be properly performed so that the severity of the offence could be minimized to the least degree. It is for this reason, the present paper reports on a small empirical study concerning the realization patterns of English apology strategies by a Chinese English learner. It reveals that the apology strategies used by a Chinese EFL learner generally fit within the theoretical framework of the five strategies developed by Olshtain and Cohen (1983). On the other hand, there are also some nuances in the use of strategies and intensifiers, when the modification of the social and contextual variables occurs.
\end{abstract}

Keywords-apology strategies; Chinese EFL learners; pragmatic competence

\section{INTRODUCTION}

The call for the mastery of English communicative skills may reflect a significant change in the EFL teaching in China. It is advocated, by the present authorities, to conduct a shift of teaching from the former exclusive focus on linguistic knowledge to a more integrated part that involves in linguistic, pragmatic and sociolinguistic knowledge. Since language learning will never be so easy as linguistic input and output, equally important, it also concerns with the relationship between a learner and the social context, and the utterance and its speech act. Normally, the third dimension--pragmatics---becomes a even more relevant research field, when linguistic competence of a L2 learner is requested to be improved in that quite a number of studies have demonstrated that the lack of some necessary pragmatic strategy knowledge may fail non-native speakers to convey their intended communicative acts in spite of their good command of vocabulary and grammar (Sullivan 1979; House 1982; Thomas 1983; Wolfson 1981; Blum-Kulk 1982; Freundlich 1981 ).

Due to his insufficiency in linguistic realization rules as well as social-appropriateness rules, a Chinese L2 learner, more often than not, opts to make an offence unconsciously in their daily conversation with a native speaker. In order to restore harmony, as is disputed by Wolfson (1989), the act of apologizing must be properly performed so that the severity of the offence could be minimized to the least degree. It is for this reason, to help Chinese L2 learners become more sociolinguistically competent, that this particular research title is selected accordingly.

\section{REVIEW OF LITERATURE}

As an act of expressing a regret, speech act of apology has long attracted the attention of scholars dealing with social and cultural patterns which has intrigued quite a number of studies on this filed. Most of the research has been conducted from three perspectives---cross-cultural, single language, or interlanguage pragmatic approach.

Amongst them, considerable quantities of studies of this kind have been investigated in the field of cross-cultural pragmatics (Deutschmann, 2003) to compare the use of apology speech act between native English speakers and native speakers of other languages. The Cross Cultural Speech Act Realization Pattern project (CCSARP) initiated by a group of researchers is of great significance within this domain. The project which looked into apologies and requests in eight languages (American English, Australian English, British English, Canadian French, German, Hebrew, and Russian ) drew a conclusion that little variation, in the case of apologies, was found in the use of the five main apologies across languages studied, and exhibited, at the same time, "surprising similarities in IFID [Illocutionary Force Indicating Device] and expression of responsibility preferences" (Olshtain, 1989, p. 171). However, it was contradicted with Olshtain and Cohen's claim (1983) which, by comparing apology situations in English and Hebrew, argued that an apology in Hebrew is less likely to include the two strategies: "an offerer of repair" and "a promise of forbearance" than in English.

The concern of this paper is just on interlanguage pragmatic apology studies that primarily examine language learners' production of the target language as a second or foreign language. Through the comparison of the speech act of apology between Danish learners of English and native English speakers, Trosborg (1987) indicated that NNS notably are dissimilar from native English speakers in their use of modality markers. Then, a DCT and assessment questionnaire completed by Bergman and Kasper (1993) in Thailand showed that a closer relationship between two 
interactants would make offender acknowledge more responsibility for the offensive act. Based on the preceding Bergman and Kasper's (1993) study, Maeshiba et al. (1996) observed the pragmatic transfer from L1 to English. Likewise, after analysing the Korean EFL speakers' apology realization patterns in terms of different social variables, Kim (2001) recognized that the social factors (social distance, social status, age, gender and severity of offence) which may influence apology behaviours is stemming from the pragmatic transfer of their first language norms.

The present paper reports on a small empirical study concerning the realization patterns of English apology strategies by a Chinese English learner since few research has been done in this area. The goals of the project are small attempts, first, to validate five main apologetic strategies that the informant employed in realizing the speech act of apology in English under differentiated social constraints, and then if possible, to further examine whether a Chinese NNS will apologize differently by adopting varied pragmatic strategies and modifications in two contrastive contexts of three different types (shown in table 1). Finally, we hope to draw some pedagogical implications from the findings.

\section{RESEARCH DESIGN}

To fulfill the goals we have set, a small empirical study is required so as to assess how a Chinese English learner realize the speech act of apology by making use of strategies addressed in the literature framework.

\section{A. Subject}

The intermediate-level learner investigated in this research is a Chinese native-speaker who completed his bachelor degree at North-western Poly-technical University, English major. In the year of 2005 upon his graduation, he worked as project manager in a China-based corporation which may provide him two or three short trips, with each trip lasting seven days maximally, per year to oversea English-speaking countries for business. Apart from that, he might have occasional exposure to the use of spoken or written English when a contact with his oversea customers was needed and this was done either by a email or a phone call.

\section{B. Instrumentation}

A role-play consisted of six different scenarios are employed in this paper, each of which concludes an offensive action. And each situation that may lead to a speech act of apology is distinct from one another by the varied deployment of the following social and contextual variables.

1) Degree of the severity of the offence: non-severe vs. severe $(-R,+R)$

2) Degree of the familiarity between interactants: unfamiliar vs. familiar $(+D,-D)$

3) Degree of the social power between interactants: non-equal status vs. equal status $(+P,-P)$

Resulted from an intentional design of combination of the above-mentioned variables, six various situations are elaborated. By doing so, we seek to further examine will a Chinese L2 learner react differently by using various pragmatic strategies when two of the three variables remain constant but left the other alternatively changed. Thus, the six situations could be sub-divided into three groups, with each group including two contrastive version of situation so that the expected findings could be revealed in the end. A description of the six scenarios in light of the severity of the offence, the familiarity and the social power between interlocutors, and its corresponding sub-goal is presented in "Table 1".

TABLE I. DESCRIPTION OF APOLOGY SCENARIO AND ITS FURTHER RESEARCH PURPOSE

\begin{tabular}{|c|c|c|c|c|c|c|}
\hline Group & Item & Offence & Severity of Offence & Familiarity & Social Power & Research Purpose \\
\hline \multirow[t]{2}{*}{$\mathrm{I}$} & 1 & to bump others & non-severe & unfamiliar & equal status & \multirow{2}{*}{$\begin{array}{l}\text { To examine whether a NNS apologize } \\
\text { differently in two contrastive contexts }\end{array}$} \\
\hline & 2 & to be late & non-severe & unfamiliar & non-equal & \\
\hline \multirow[t]{2}{*}{ II } & 3 & car accident & severe & familiar & non-equal & \multirow{2}{*}{$\begin{array}{l}\text { To examine whether a NNS apologize } \\
\text { differently in two contrastive contexts }\end{array}$} \\
\hline & 4 & to break the gift & severe & familiar & equal status & \\
\hline \multirow[t]{2}{*}{ III } & 5 & to hit the head & severe & unfamiliar & equal status & \multirow{2}{*}{$\begin{array}{l}\text { To examine whether a NNS apologize } \\
\text { differently in two contrastive contexts }\end{array}$} \\
\hline & 6 & to break the cup & severe & unfamiliar & non-equal & \\
\hline
\end{tabular}

The appendix affiliated contains a sample of detailed six different scenarios and its transcripts.

\section{Data Collection Procedure}

The informant was required to the largest possible extent to situate himself and reply the role play questions with his authentic thoughts. And he, however, was not informed that it was the speech act of apology that the researcher was interested in. The ultimate aim of the role-play is to obtain data which were as spontaneous and natural as possible, to accomplish it, two adjustments were specially devised and added in the procedure.
After the tester read the situation, the investigator began to role-play with the interlocutor who supposed to perform the speech act of apology. Besides, elicited technique would be naturalized during the entire interview to yield sufficient responses. In this way, the informant would avoid using indirect speech that is likely to result in interference and deviation in expressing his/her real meaning.

The role-enactment, conceded by McDonough (1981), is regarded as the most advantageous approach to gain natural data, as it refers to a tailor-made role-play which embodies questions and characters that the participant ought to be well acquainted with. Therefore, in line with McDonough's (1981) 
theory, many questions and details closely linked with the informant's daily life and work are involved so that it could trigger adequate natural utterances.

The dialogue between two interlocutors will be taperecorded, and then transcribed and analysed with reference to the taxonomy of apology strategies provided by Olshtain and Cohen (1983). Additionally, utterances classified within the theoretical framework are further compared and contrasted with an aim to explore whether a Chinese NNS will apologize differently by adopting varied pragmatic strategies in two reverse contexts.

\section{Data Analysis}

In this project, the Chinese EFL's apology strategies was coded in accordance with the model developed by Olshtain and Cohen (1983) since its universal applicability to various languages has been successfully and empirically verified. According to Olshtain and Cohen (1983), an offender would possibly choose either a single or combination of the following strategies, supposing that he/she assumed the responsibility for the offence committed.

\section{1) An expression of apology.}

a) An expression of regret. e.g. I should not do that.

b) An offer of apology. e.g. I apologize.

c) A request for forgiveness. e.g. Forgive me.

2) An explanation or account of the situation. e.g. The clock was stopped.

3) An acknowledgement of responsibility

a) Accepting the blame. e.g. I should be responsible.

b) Expressing self-deficiency. e.g. I was confused .

c) Recognizing the other person as deserving apology. e.g. You are right. purpose.

d) Expressing lack of intent. e.g. I am not with a
4) An offer of repair. e.g. I may buy you a drink.

5) A promise of forbearance. e.g. It won't happen again.

On the contrary, if the offender denys the need to apologize, he/she may not react or just has a verbal reply which is likely to be:

- A denial of the need to apologize. e.g. This is no big deal!

- A denial of responsibility

A. Not accepting the charge. e.g. I was not responsible for that.

B. Blaming the other interlocutor. e.g. It's your own fault.

It should be also noted that in addition to the apology strategies and sub-strategies encompassed in this model, other strategies may also be observed in the data, such as the internal and external modifications employed to intensify the tone. Hence, analysis of the data will be proceeded in three three dimensions---main strategies, intensifications and combination strategies.

\section{FINDINGS AND DISCUSSION}

\section{A. Main Strategies and Intensifications}

As far as the first research question is concerned, the data shown in table 2 has evidently demonstrated what pragmatic strategies have been adopted when the intermediate-level Chinese NNS of English apologized in different situations. The strategy model explored by Olshtain and Cohen (1983) were, on the whole, manifested in the collected data. What is more, from table 2 we can also find none of the six apology realization patterns is completed by a single selection of one strategy, instead, they all come in a combination of more than two strategies.

TABLE II. Distribution OF APOLOGY STRATEGIES USED By the INFORMANT

\begin{tabular}{|c|c|c|c|c|c|c|}
\hline Apology Strategies & Situation 1 & Situation 2 & Situation 3 & Situation 4 & Situation 5 & Situation 6 \\
\hline \multicolumn{7}{|l|}{ 1). An expression of apology } \\
\hline \multirow{2}{*}{$\begin{array}{l}\text {-A. An expression of regret. } \\
\text {-B. An offer of apology. } \\
\text {-C. A request for forgiveness. }\end{array}$} & $\sqrt{ }$ & $\sqrt{ }$ & $\sqrt{ }$ & $\sqrt{ }$ & $\sqrt{ }$ & $\sqrt{ }$ \\
\hline & & & & & & \\
\hline 2).An explanation or account of the situation & $\sqrt{ }$ & $\sqrt{ }$ & & & $\sqrt{ }$ & $\sqrt{ }$ \\
\hline \multicolumn{7}{|l|}{ 3).An acknowledgement of responsibility } \\
\hline \multirow{4}{*}{$\begin{array}{l}\text {-A. Accepting the blame. } \\
\text {-B. Expressing self-deficiency. } \\
\text {-C. Recognizing the other person as deserving apology. } \\
\text {-D. Expressing lack of intent. }\end{array}$} & & $\sqrt{ }$ & & & & \\
\hline & & & & $\sqrt{ }$ & & $\sqrt{ }$ \\
\hline & & & & & & \\
\hline & & & & & & \\
\hline 4). An offer of repair & & & $\sqrt{ }$ & $\sqrt{ }$ & $\sqrt{ }$ & $\sqrt{ }$ \\
\hline 5). A promise of forbearance & & & & & & \\
\hline
\end{tabular}

Further, we seek to explore more on the discrepant usages of each strategies, combination strategies or intensifiers when the social or contextual variables change to address the second research issue.
1) An expression of apology.

As presented in table 3, Of the five strategies, the use of "an expression of regret" occurs in all scenarios. This may reflect the informant's semantic formula preference of making an explicit apology. At this point, he may have no difference from that of a native speaker, as it is recognized 
that the most frequent IFID in English is an expression of regret (Owen, 1983; Blum-Kulka and Olshtain, 1984). However, with the social variables altering in situations, the participant are found to use different intensifications with purpose. For example, in scenario 1 (to bump others) and scenario 2 (to be late), where severity of offence (non-severe) and familiarity (unfamiliar) is kept constant but the social power is set changeable, the internal intensification (e.g. I am terribly sorry) is only employed in the former one.

\section{2) An explanation.}

Followed by "an expression of apology", "an explanation" is the second most frequently utilized strategies which are only absent from situation 3 (car accident) and 4 (to break the gift). The setting of this two situations are identical in terms of severity of offence (severe) and familiarity (familiar), but the social power between two interactants is unequal. In both situations, though "an explanation" is omitted, the emergence of "an offer of repair" and intensifications might be regarded as an substitution to show the speaker's sympathy. For instance, in situation 3, "I am quite sorry that (internal intensification of adverbial)...and I have got it repaired (an offer of repair)..., ...I am so sorry about that (adverbial and repetition)". Similarly, in situation 4, "Tom, I am so sorry about your beer glass(internal intensification of adverbial)..., and I will try my best to get a new one for you from Egypt (an offer of repair)".

TABLE III. THE FREQUENCY OF APOLOGY STRATEGIES OCCURRENCE

\begin{tabular}{|l|l|l|}
\hline \multicolumn{1}{|c|}{ Apology Strategies } & Frequency & $\begin{array}{c}\text { Total Items of } \\
\text { Situations }\end{array}$ \\
\hline 1). An expression of apology & 6 & 6 \\
\hline $\begin{array}{l}\text {-A. An expression of regret. } \\
\text {-B. An offer of apology. }\end{array}$ & 6 & 6 \\
\cline { 2 - 3 } -C. A request for forgiveness. & 0 & 6 \\
\cline { 2 - 3 } $\begin{array}{l}\text { 2). An explanation or account of } \\
\text { the situation }\end{array}$ & 0 & 6 \\
\hline $\begin{array}{l}\text { 3). An acknowledgement of } \\
\text { responsibility }\end{array}$ & 3 & 6 \\
\hline -A. Accepting the blame. & & 6 \\
\hline -B. Expressing self-deficiency. & 1 & 6 \\
\hline $\begin{array}{l}\text {-C. Recogni zing the other person as } \\
\text { deserving apology. }\end{array}$ & 2 & 6 \\
\cline { 2 - 3 } -D. Expressing lack of intent. & 0 & 6 \\
\hline 4). An offer of repair & 1 & 6 \\
\hline 5). A promise of forbearance & 0 & 6 \\
\hline
\end{tabular}

\section{3) An offer of repair.}

Same with "an explanation", "an offer of repair" is only absent in two situations, where the two interlocutors hardly know each other $(+\mathrm{D})$, the offence is severe $(-\mathrm{R})$ and the social power $(+\mathrm{P},-\mathrm{P})$ between the two interlocutors varies alternatively. With respect to the use of intensifiers, only in the case when the hearer has the dominance over the speaker, it will be utilized, as in situation $2(-\mathrm{R},+\mathrm{D},+\mathrm{P})$, "Manager, $\mathrm{I}$ am terribly (intensifier) sorry about my coming late for this appointment".

\section{4) An acknowledgement of responsibility.}

Indicated in table 3, "an acknowledgement of responsibility" is the fourth most frequently used strategy. Its occurrence in situation 4 and 6 (seeing below) where both two interlocutors are well acquainted with each other may justify Kasper's (1993) study that claimed a closer relationship between two interactants would cause offender acknowledge more responsibility. Extracts in this regard from situation $4(+\mathrm{R},-\mathrm{D},-\mathrm{P})$ and $6(+\mathrm{R},+\mathrm{D},+\mathrm{P})$ are the same, "...I was so careless (intensifier and expressing selfdeficiency)...". While the different sub-strategy adopted in situation $2(-\mathrm{R},+\mathrm{D},+\mathrm{P})$ when acknowledging responsibility may indicate, in this case, that a Chinese NNS may intend to express the acception of the blame explicitly when the speaker and hearer have unequal social power.

\section{5) A promise of forbearance.}

Interesting enough, "a promise of forbearance" has a zero occurrence among all six scenarios, and this finding is quite similar with that of Anna Trosborg's (1987) who revealed, from his study, that "a promise of forbearance" is not frequent neither in native speaker of English group nor nonnative English group.

\section{B. Combination of Strategies}

In fact, from table 2, we can also find none of the six scenarios is only engaged in the use of a single strategy. With the severity of the offence turning from non-severe to severe, the number of the combination strategies raised accordingly. As Olshtain and Cohen (1983) claimed, people often combine two or three apology strategies together to facilitate their apology speech act. Thus, in order to minimize the degree of offence, the use of a single strategy is apparently inadequate for the participant to fully achieve the purpose. A typical example for the use of multiple-strategies found in my data would be either "an expression of regret" plus "an explanation" (e.g. I am sorry. there too much traffic.) or "an expression of regret" plus "an offer of repair"(e.g. I am sorry. I will get you a new one).

\section{CONCLUSION}

The findings of this study reveal that the apology strategies used by a Chinese EFL learner generally fit within the theoretical framework of the five strategies developed by Olshtain and Cohen (1983). On the other hand, there are also some nuances in the use of strategies and intensifiers, when the modification of the social and contextual variables occurs Internal intensifiers emerge from all scenarios except the first one but the utilization of external intensifiers does not go through the same high frequency, and this may mark an area where the informant need some pedagogical intervention. Regarding the informant's specific use of the strategies which are distinct from others, like the zero occurrence of the use of "an offer of apology" and "a request for forgiveness", it might be ascribed to his special cultural values and social norms. Hence, a pedagogical conclusion could be drawn that, as a lecturer, we should foreground activities in classroom that incorporate different social and contextual variables so that learners would be more sensitive to various sociocultural meanings of the NS. Lastly, I have to acknowledge the biggest limitation of this study ---a rather small population of the participants through which it is hardly to make any comparative studies. 


\section{REFERENCE}

[1] Bergman, M., \& Kasper, G. (1993). Perception and performance in native and nonnative apology. In G. Kasper \& S. Blum-Kulka (Eds.), Interlanguage Pragmatics (pp. 82-107). New York: Oxford University Press.

[2] Blum-Kulk, S. (1982). Learning to say what you mean in a second language: a study of the speech act performance of Herbrew Second Language Learners. Applied Linguistics, 3, 29-59.

[3] Blum-Kulka, S., \& Olshtain, E. (1984). Requests and apologies: a cross-cultural study of speech act realization patterns (CCSARP). Applied Linguistics, 5, 196-213.

[4] Deutschmann, M. (2003). Apologizing in British English. Umea University: Tryckt av Print.

[5] Freundlich, J. Y. (1981). No thyself: the art of refusal. Rutgers University.

[6] House, J. (1982). Conversational strategies in German and English dialogues. Error analysis. In G. Nickel. \& D. Nehls (Eds.), Constructive Linguistics and Second Language Learning (pp. 18-35). Rowley Mass:New Burry House.

[7] Kim, D., K. (2001). A Descriptive Analysis of Korean and English Apologies with Implications for Interlanguage. $\mathrm{PhD}$ Dissertation, University of Florida.

[8] Maeshiba, N., Yoshinaga, N., Kasper, G., \& Ross, S. (1996). Transfer and proficiency in interlanguage apologizing. In S. Gass \& J. Neu (Eds.), Speech acts across cultures: Challenge to communication in a second language (pp. 155-187). Berlin: Mouton.

[9] McDonough, S. H. (1981). Psychology in Foreign Language Teaching. P-80. London: George Allen and Unwin.

[10] Olshtain, E., \& Cohen, A. (1983). Apology: A speech act set. In N. Wolfson \& E. Judd (Eds.), Sociolinguistics and Language Acquisition. Rowly: Newbury House.

[11] Olshtain, E. (1989). Apologies across languages. In S. Blum-Kulka, J. House \& G. Kasper (Eds.), Cross-Cultural Pragmatics: Requests and Apologies (pp. 155-174). Norwood: Ablex.

[12] Owen, M. (1983). A Study of Language Use in Social Interaction. Berlin: Mouton.

[13] Sullivan, P. (1979). Conversation: saying hello and goodbye. TESOL Newsletter, 13(29).

[14] Thomas, J. (1983). Cross cultural pragmatic failure. Applied Linguistics, 4, 91-112.

[15] Trosborg, A. (1987). Apology strategies in natives/non-natives. Journal of Pragmatics, 11, 67-144.

[16] Wolfson, N. (1981). Compliments in cross-cultural perspective. TESOL Quarterly 15, 117-124. 